University of Louisville

ThinkIR: The University of Louisville's Institutional Repository

College of Arts \& Sciences Senior Honors

Theses

College of Arts \& Sciences

$5-2013$

\title{
Ethical imperatives of teaching stress control to promote well- being.
}

Clayton Coleman

University of Louisville

Follow this and additional works at: https://ir.library.louisville.edu/honors

Part of the Philosophy of Mind Commons, and the Psychiatric and Mental Health Commons

\section{Recommended Citation}

Coleman, Clayton, "Ethical imperatives of teaching stress control to promote well-being." (2013). College of Arts \& Sciences Senior Honors Theses. Paper 8.

http://doi.org/10.18297/honors/8

This Senior Honors Thesis is brought to you for free and open access by the College of Arts \& Sciences at ThinkIR: The University of Louisville's Institutional Repository. It has been accepted for inclusion in College of Arts \& Sciences Senior Honors Theses by an authorized administrator of ThinkIR: The University of Louisville's Institutional Repository. This title appears here courtesy of the author, who has retained all other copyrights. For more information, please contact thinkir@louisville.edu. 


\section{University of Louisville}

Ethical Imperatives of Teaching Stress Control to Promote Well-Being

\section{Clayton Coleman}

\section{Senior Honors Thesis}

"Vane is the word of the philosopher that does not heal any suffering of man" 
The overarching purpose of this thesis is to explain why the creation of a program that facilitates and maintains good mental health is ethically imperative. This paper will focus on the ethical primacy of mental health within a population as opposed to physical health. A key factor that this paper will take into account is the way that stress affects physical health and how stress is disproportionately spread through the population. It recognizes that an individual's mental health status can be influenced by their particular life circumstances and/or socioeconomic status, which can be seen as constitutive luck. Those disadvantaged segments of the population negatively affected by stress are not only inhibited intellectually, but also physically. This lack of proper health causes a lack of opportunities, which constitutes a social injustice. Moving from the establishment of this disparity, this thesis proposes solutions that would, in turn, seek to rectify these social injustices in ways that are equitable and fair to those who are the least well off in society.

\section{Definitions}

Stress has always been, and continues to be, an everyday occurrence within the human population. However, certain segments of the population are affected differently, and in various degrees, in comparison with others. The magnitude and impact of stress is closely related to the socioeconomic status that an individual holds. Throughout this paper socioeconomic status (SES) will refer to the relative social position of an individual based upon their income, education, and occupation. While race is not explicitly attached to SES there is a high correlation between minority race status and low SES. 
In the vernacular, stress can be very ambiguous, but it is most readily defined as the body's reaction to external or internal pressures manifested by mental and physical arousal characterized by increased blood pressure and muscle tension. These manifestations are typically seen in a negative light. However, at low levels, stress can be beneficial to a person and his or her performance. This beneficial low level of stress is known as eustress. On the other hand, distress is high levels of stress that impact the body's natural function because of an individual's lack of ability to cope. Chronic distress can fatigue the body systems to the point of malfunction and disease. ${ }^{1}$ Throughout this thesis the term stress will refer to the technical term distress and its subsequent physical effects.

The conception of stress referred to in this paper is important because of the consequences it has on certain sections of populations. Research shows that people of lower socioeconomic status have higher levels of daily stress than their counterparts. People who fall into a lower SES are more likely to incur higher levels of stress due to a multitude of reasons including monetary, residential, and marital instability. ${ }^{2}$ These fluctuations in daily living create an environment that causes chronic stress. Chronic stress is a dysfunctional state that contributes to a higher rate of sickness and as well as metal and physical problems throughout life.

\section{The Stress Response}

It is important include a brief description of how stress affects the body. The stress response is activated when a mammal perceives a stressor. For non-human mammals a stressor is typically a threat posed by a predator. This threat causes an 
intricate series of reactions to occur in the body. A stressor typically begins by with an audible or visual arousal. The hypothalamus reacts to this arousal by secreting Corticotropin-releasing hormone $(\mathrm{CRH})$. $\mathrm{CRH}$ then activates the pituitary gland, which releases adrenocorticotrophic hormone (ACTH). ACTH is sent into the blood stream and interacts with the Adrenal Cortex. ACTH activates the adrenal glands causing the release of cortisol, aldosterone, and epinephrine, which is commonly known as Adrenaline. This three-step hormonal process is known as the HPA-axis. The HPA axis process results in the commonly known fight-or-flight response, which continues until the perceived stressor is alleviated.

The fight-or-flight response is important to note because of how it affects humans. In animals the fight-or-flight response is a fast occurring and resolved process. A stressor causes a dumping of cortisol, aldosterone and epinephrine into the bloodstream. These hormones cause reactions throughout an animal's body by activating the sympathetic nervous system. They divert blood from the skin and digestive system to muscles vital for action. Fat cells dump their contents into the blood stream so these muscles can rapidly absorb energy needed to act. Heart rate increases as blood carries the necessary oxygen and nutrients to muscles throughout the body. An aroused sympathetic nervous system causes clearer thinking, faster response times, and sharper vision. ${ }^{3}$

Once the crisis is averted the Hypothalamus stops the secretion of CRH and the HPA-axis becomes dormant until the next arousal. Why is this natural occurrence important to a thesis on stress control? It is important because humans, like every other mammal experience the fight-or-flight response. However, humans can experience this 
hormonal interaction without any real or perceived threat. The very thought of a perceived threat can create this response in the body that causes individuals to prepare and react to situations. Furthermore, the fight-or-flight response is not limited to thoughts of physical harm. It can also be caused by social and psychological threats or damages. Humans, unlike other mammals, constantly think about their environment and perceived threats that lie within. This can be as basic as getting mugged on the street, as simple as worrying about the condescending "tweet" they just received from a friend, or as complex as worrying about how to pay the mortgage due in two days. ${ }^{4}$

The problem with all of these situations is that they are hardly ever resolved in a prompt manner. Levels of stress are changed by three factors: frequency, intensity, and duration. The two that are most important to this thesis are frequency and duration. Frequent bouts of stress cause the sympathetic nervous system to engage more often. Duration compounds this by extending the nervous system activity over a long period of time. Humans cannot escape from problems like a zebra escapes a lion trying to make them lunch. People ruminate on problems, which creates continually high levels of sympathetic nervous system activity.

The hypothalamus continually perceives a threat, therefore continues to prompt the adrenal glands to secrete its hormones. These hormones are beneficial in the short term, but they are extremely detrimental in the long term. Chronic stress results in damaged cognitive ability, fatigue, depression, hypertension, heart disease, decreased antibody production, and muscle wasting. An additional problem created by unmitigated stress is depression. Studies show that there is a correlation to high levels of stress and the development of a depressed state. ${ }^{5}$ This exemplifies how mental 
health can be more important that physical health because an unresolved mental health burden creates physical problems.

\section{Constitutive Luck and Health Care Disparities}

The discrepancy in health according to SES is an extremely important factor to take into consideration when addressing stress and its long-term effects. This disparity is highlighted by two forms of luck found within Thomas Nagel's concept of moral luck. These two types are constitutive luck and luck in circumstances. ${ }^{6}$

Constitutive luck, according to Nagel, is "the kind of person you are, where this is not just a question of what you deliberately do, but of your inclinations, capacities, and temperament."(Nagel 30) In other words, how a person relates to the world is somewhat predetermined by physical and social aspects that they had no hand in producing. A factor important to this thesis is that this could be interpreted as a predisposition to mental illnesses or the lack of mental capabilities to cope with stress and/or function properly within society. Also, the cognitive abilities that people have, or lack, can change the way in which they perceive their environment. Over time, these preconditions can contribute to and exacerbate mental, emotional, and social problems.

The second category of luck Nagel writes about is luck in circumstances. Luck in circumstances refers to the surroundings, situations, and moral problems that an individual faces in life. These are caused, in large part, by circumstances outside of their control. At birth, a person is placed into an environment, which produces a variety of circumstances that can either encourage or discourage mental, physical, and 
emotional flourishing. By the time a person develops consciousness and the capability to choose their decisions have, in essence, already been decided for them.

Nagel's conception of luck can be clarified with a simple thought experiment. For instance, take two children born into the world at the same point in time, in the same country, with all circumstances held the same including gender, race, sexuality, and a genetic predisposition to mental illness. The factor that is dissimilar to both children is their parents' socioeconomic status. Now, imagine that both live a life where they develop a mental dysfunction such as anxiety and depression at the typical age of thirteen. ${ }^{7}$ At that point, the child whose parents have a high socioeconomic status is given an advantage. His parents have the financial means and ability to provide him with the resources necessary to combat his mental ailment. On the other hand, the child born into a lower SES is at a disadvantage. His parents can provide him with the necessary emotional support but they lack the necessary fiscal support needed to provide him with proper counseling, training, or even medication.

The increased stress, combined with a genetic predisposition can lead to depression. This depressed state could burden the child with a mental mindset that creates a lack of continuity in expectations and motivation. This scenario only proves to be problematic for the child with lower means. Developing a mental illness like depression only exacerbates the current fiscal disadvantage throughout life. The child whose socioeconomic status is lower is further encumbered by a recurring mental burden. Once again the situation only intensifies as time passes because of a lack of resources needed to address this problem. 
This thought experiment displays the disparity that many children in society currently face. There is a lack of knowledge to prevent or mitigate these problems before and after they develop. Also, there is a scarcity of necessary fiscal support from parents and governmental institutions that could potentially improve children's circumstances by helping them to develop proper coping mechanisms. The resulting situation produces an injustice for a multitude of children merely because of the socioeconomic status they were born into due to their constitutive luck. The primary challenge created by this inequality in circumstances is the impediment of mental health. This, in turn, can cause physical problems. Throughout the course of the children's life there is not only a original advantage gained by the child whose parents are a higher SES, there is also compounding disadvantage for the child of low SES because of unaddressed mental problem.

\section{Justice and Health Care Disparities}

The reason this thought experiment exemplifies an injustice inequality is found in Norman Daniels' theory of Just Health. Daniels develops this conception of justice in health by extending Rawls' Theory of Justice. Rawls approaches the creation of a just society with the use of a complex thought experiment. He begins with the establishment of the original position. The original position is a group comprised of disembodied rational actors, each vying for their own personal interests. They have no knowledge of what their personal circumstances will be once the society is created. This can be likened to the fact that no person has a hand in choosing his or her constitutive luck. Furthermore, the beings in the original position do not have a prior 
knowledge of what constitutes a good within their society. They do not know what their personal desires might be once they have been placed into the society they have developed. These factors present in the original position create what Rawls' calls the "veil of ignorance". This veil is a key factor in the creation of a just society.

Rawls structures this new hypothetical society with the use of two principles of justice. He states them as such, "First: each person is to have an equal right to the most extensive basic liberty compatible with a similar liberty for others. Second: social and economic inequalities are to be arranged so that they are both (a) reasonably expected to be to everyone's advantage, and (b) attached to positions and offices open to all.” (Rawls 60) These two principles of justice combined constitute what is known as the maximin principle. The maximin principle deals with distribution of burdens and benefits in society. It seeks to minimize the burdens and maximize the benefits of the least well off in society. Also, it creates a structure where an individual cannot benefit disproportionately to the burden it causes the less fortunate within the system. It acts as a buffer to keep inequalities from becoming so drastic that they cannot be overcome.

The rational beings create this society but they do not choose where they are placed. Instead they must assume that a malevolent person will assign them their position. Thus, it prompts the rational being to structure society in more equitable ways. The being would not want to create a system that has large disparities in social hierarchy. The rational beings would not want limit social mobility within their society out of fear of self-interest. Disparities in the social structure would not be so stark as to limit those who are born with a certain social skill set at the bottom of the societal structure. Ultimately, for society to be just, an individual who is born at the bottom of 
the structure has an equal chance as someone who has been born at the top to end up at the top at the end of his or her lifetime. This requires that primary social goods be distributed in a fair and equitable manner. ${ }^{8}$

The idea of a fair and just society hinges upon the protection of opportunities. The opportunity to pursue desired goals and ultimately become socially or fiscally well off without being inhibited by the social structure. Daniels extends this protection of opportunity argument by noting that health is necessary to protect the normal opportunity range. This is where Daniels' normal functioning argument comes into play. Normal functioning helps to ensure social movement within society, thus it is necessary to ensure justice, because it is required by the maximin principle. People in disadvantaged situations must be able to maximize the primary goods they have in an effective manner.

According to Daniels, Health is of prime importance because the lack of proper health limits a person's opportunities throughout life. If people have appropriate health they are freer to pursue a wider range of opportunities. Thus, a lack of proper health creates an inhibition. Adhering to the idea of normal functioning, Daniels contends that there is also a normal opportunity range or the extent to which people can expect to pursue what they desire given their talents and abilities are sustained throughout life. $^{9}$

As previously described, stress over a lifetime can compound and exacerbate health problems. Chronic stress, which is a mental malfunction, decreases immune system function, and simultaneously increases the risk of hypertension, heart disease, and stroke. Even though all of the problems can be experienced at all levels of society 
they once again are aggravated by income level. People of low SES have higher amounts of chronic stress because they are in a disadvantageous social and fiscal environment, which causes more life decisions with a higher level of importance. ${ }^{10}$

Chronic stress is problematic because it contributes to poorer health through the detriment of mental health. Mental health is not solitary; rather it buttresses all other aspects of health. This detail warrants more attention than many other policies, outside those that provide for basic sustenance. The argument for the promotion of proper mental health relies upon Norman Daniels' conception of normal functioning. Normal functioning is determined by the degree to which it deviates from the norm within a population. It is not merely the lack of disease, but more closely tied to proper functioning in all contexts of life. Norman Daniels reasons that health is the maintenance of normal functioning throughout life. However, Daniels' idea of normal functioning is limited to maintenance of proper physical health. This thesis conceives of proper physical health as secondary to proper mental health. A lack of proper mental health can create disastrous affects on physical health, which is enumerated in the stress response section.

\section{Achieving Normal Functioning}

Daniels focuses on the achievement of normal functioning through the use of six tenets. However, all of these tenets address specifically physical aspects of normal functioning rather than its equally important counterpart, proper mental functioning. These tenets, viewed from a perspective adherent to the importance of mental health can be extremely useful. Explicitly these are, “(1) Adequate nutrition (2) Sanitary, safe, 
unpolluted living and working conditions (3) Exercise, rest, and such important lifestyle features as avoiding substance abuse and practicing safe sex (4) Preventive, curative, rehabilitative, and compensatory personal medical services (5) Nonmedical personal and social support services (6) An appropriate distribution of other social determinants of health" (Daniels 42) Of these six basic health needs, numbers 3-5 are all aided or met through the implementation of proper stress coping techniques.

Daniels' third tenet includes the concept of rest. Rest, as it pertains to stress, is not simply the ability to sleep but to decrease sympathetic nervous system activity, or fight-or-flight response. While proper sleep is important, the ability to achieve actual rest is dependent upon one's ability to divest oneself of tension and allow the parasympathetic nervous system to overtake an exhausted sympathetic nervous system. This requires that a person have the ability to concentrate and focus their mental state to a point where their muscles fully release tension. Their mind must become blank or fixated upon a central idea such as a prayer or mantra rather than the mass of ideas and thoughts of daily living.

This conception of rest is indeed a difficult state to achieve in current society, where continual stimulation and input barrage the mind and body. It is very unlikely that a person will have the knowledge that is needed to enter such a state and garner its mental and physical benefits. That is why the next tenet of preventative services plays such an important role. The common conception of preventative services is a system that functions to provide people with health knowledge, vaccinations, and simple services that help maintain health. However, a true system of preventative services 
goes one step further by actively engaging people in the process that helps them to develop habits necessary to avoid the onset of disease.

Health and exercise are important, but as demonstrated earlier so is the maintenance of proper mental health. Over time, the constant bombardment of stressful life events, without proper reduction or alleviation, can lead to higher amounts of sickness and disease. In fact, on at least one account, 60 to 90 percent of all visits to a doctor can be attributed to stress-related symptoms. ${ }^{11}$ This means a population that is dependent upon being present at work to make their hourly wage must take time off to seek medical attention for themselves or their children. Then, once, or if, these populations reach old age there is a greater likelihood of them having chronic diseases such as hypertension or diabetes. Furthermore, this group becomes more vulnerable to heart disease and stroke because of chronic stress. ${ }^{12}$

\section{Stress Reduction Techniques}

There are many varieties of methods that can be used to reduce the sympathetic nervous system and elicit a parasympathetic nervous system response. These techniques include, but are not limited to meditation, biofeedback therapy, exercise, and even psychological training techniques such as cognitive behavior therapy.

There are many forms of meditation but this thesis will focus on the form of meditation pioneered by Herbert Benson known as the Relaxation Response. Benson first published his method over forty years ago and has since then continued to produce research on its benefits. Within his book he describes, in detail, the effects of stress on the body, which are delineated earlier in this paper. He also explains various 
coping mechanisms to help reduce that stress. Benson recognized that stress invariably plays a part in every person's life, but he does not believe it should cripple an individual's capabilities. Through research, trial, and error, Benson was able to distill a simple technique designed to elicit what he called the relaxation response.

In order to achieve the relaxation response there must be four components, a quiet environment, an object or phrase to dwell on, a passive attitude, and a comfortable position. Any person, regardless of age, can use these four elements to increase their parasympathetic nervous system response, and create a relaxed state. People seeking this relaxation response only need to be placed in a calm environment, which can be found or manufactured. Manufactured in the sense that a quiet area can be sustained by an authority figure. However, once self sufficient, an individual can guide himself or herself through the simple process by concentrating on their breath and repeating a phrase such as "peace" or "calm" with each exhale. ${ }^{13}$

Another very useful tool to help people recognize and alleviate stress is biofeedback therapy. A basic description of biofeedback therapy is using machines to recognize internal stimuli or measures. This information can then be used to consciously regulate and/or change internal processes. Biofeedback therapy can be used to monitor anything from heart rate, to blood pressure, to skin temperature.

The most simplistic way to employ biofeedback therapy is by monitoring skin temperature. As described in the effects of stress section, sympathetic nervous system activation causes blood to be diverted from the skin to major muscle groups. This diversion is caused by vasoconstriction of tiny blood vessels in the extremities. The lack of blood flow actually creates an identifiable change in temperature on the skin 
surface. Thus, temperature of an extremity can be used as a gauge of sympathetic and parasympathetic nervous system activity. ${ }^{14}$

This indicator can be tracked with a simple thermometer attached to the pinky digit. An individual can begin tracking the temperature shown on the thermometer monitor for a period of time. Lower levels of heat indicate the activation of the sympathetic nervous system and elicitation of chronic stress. People using the monitors can use the information to raise their skin temperature consciously and activate the parasympathetic nervous system. As subjects become more adept at changing their hand temperature under their own volition they can begin to employ this technique without the use of the monitor. Thus, they can achieve a more relaxed state by concentrating on one element of their body without the external aid.

Another technique critical to stress control on an individual level is Cognitive Behavioral Therapy (CBT). CBT does not explicitly pertain to stress reduction through parasympathetic nervous system activation like meditation. It does however; seek to change thought and behavior patterns that contribute to the stress response. It does so by eliminating or mitigating thinking that exacerbates stressful situations. As delineated in the section on stress, human beings are unfortunate in the fact that the mere thought of a stressful situation can spur sympathetic nervous system activity. So negative or destructive thoughts can have an enormous impact on an individuals thought patterns and thus their health status.

Cognitive behavior therapy is psychological counseling technique that was begun by Dr. Albert Ellis in the 1950's. Its basic principle works from the premise that people have immediate and almost unrecognizable thought and behavior patterns. For 
example, A person may fail a test and immediately think a phrase such as "I'm an idiot", "I will never pass", "I can't do anything right" and so on. CBT recognizes that these generalized statements are immediate distorted patterns of thought. In fact, they are so immediate people rarely realize their repercussions. These thoughts can compound overtime and eventually cause a stressed or depressed state in people.

A trained cognitive behavior therapist will help individuals to realize that these thoughts are actually the result of a conditioning process that produces maladaptive coping techniques. Over multiple sessions therapists can help people to combat these distorted thoughts with proper coping strategies. Patients learn to challenge and change thoughts like "I can't do anything right" by presenting themselves with concrete examples of things they do correctly on a constant basis. They then use this challenge to help them find, and focus on, things that they do right. This technique is not a counselor dependent tool. Once CBT is learned, it can be effective utilized to mitigate stressful circumstances throughout life just like meditation and biofeedback therapy.

CBT has been shown as an effective tool in the treatment and even prevention of depression. It can be used by itself or with the aid of an anti-depressant to help patients overcome depressive symptoms. This is important because it is not only good tool to treat depression, it can also prevent it before it becomes a reoccurring problem. CBT can be a vital tool to help children with a predisposition to mental illness. It can change thought patterns and behaviors that could eventually lead to depression. ${ }^{15}$

\section{Established Mental Health Programs}


A society's ability to prevent the disparity caused by stress and depression is now found in Daniels" "Nonmedical personnel and social support services". While there are various support services riddled throughout society there is a stark lack of services devoted to the mental health of a population. One marquee program can be found in the United Kingdom, Increasing Access to Psychological Treatment (IAPT). IAPT provides a practical example of a program that views mental health as an issue of prime importance. ${ }^{16}$

IAPT was originally developed and created by Lord Richard Layard because it provided the United Kingdom with an economic incentive. The incentive was to help people return to work. Lord Layard knew that people who were stressed to the point of depression could no longer work, or if they were unemployed they would not actively seek work. This meant that there would be a large pool of citizens who were utilizing benefits without paying into the system. Thus, IAPT's primary goal was to provide United Kingdom workers with the tools to overcome stress, anxiety, and depression so they could be free to return to work and live more productive lifestyles. It has also shown to reduce costs by reducing anti-depressant medication prescriptions, general practitioner visits, outpatient appointments, and even inpatient bed days. Aside from the economic incentive provided by this program there are also many practical benefits for English citizens.

Within England there are an estimated 6 million people suffering from some mental health disorder. One in four English citizens will experience a mental health disorder in their lifetime and one in one hundred will experience a severe mental illness. This is very similar to the fact that 1 in 10 people in America will be diagnosed 
with depression and prescribed anti-depressants. ${ }^{17}$ Since the program began three years ago, IAPT has seen one million patients with mild to moderate depression or anxiety. Over half of those patients have completed their treatment. Also, IAPT claims to have helped move 45,000 people off sick pay and benefits in three years time. ${ }^{18}$

IAPT is different than many ordinary ways of treating depression and anxiety. Rather than going through a general practitioner, a person can self-refer to any one of IAPT's accredited programs. Thus, a significant portion of people who otherwise might not have been given treatment, because of an aversion to speaking with their doctor or misdiagnosis, receives proper care. Its fundamental means of treating these people is through the use of Cognitive Behavior Therapy. IAPT has trained over 4000 people to help guide the mentally ill through their time by teaching them mental strategies and techniques to cope with the stress they incur on a daily basis.

The program's assumption is that a certain percentage of people cannot work or attain outside goals due to mild or moderate depression. This once again alludes to the problem Daniels misses. A lack of proper mental health actually precludes proper physical health and this divergence constitutes a lack of opportunities. A person who cannot function well enough to work is inherently at a disadvantage. Also, this lack of ability to motivate oneself or properly function in a work setting creates a snowball effect. The more the person experiences mental hardship the less they can work, the less they can work the less means they have, the less means they have the more duress they fall into.

This cycle is exactly what Rawls and Daniels wish to avoid. If over time compounding things such as stress and mental anguish contribute to societal woes, 
should there not be a moral emphasis on preventing them before they start? Research shows that people who are born with predisposition to depression develop the disorder around the age of thirteen. Furthermore, once a person experiences a depressive episode they are more likely to experience more throughout life. ${ }^{19}$ These continuing problems should prompt a need for solutions.

\section{How this Addresses Injustice}

This disparity in mental health for previously mentioned populations constitutes inequality. On the surface this inequality may not seem unjust due to the fact that inequalities are inevitable, but it is in many fundamental ways. For instance, Daniels notes that low SES African Americans are affected disproportionately by stress due to institutional racism. He states, "Compared to white males, black males age fifty-one to sixty one have higher prevalence of hypertension, stroke, diabetes, kidney and bladder problems, and stomach ulcers; whites have a higher prevalence of cardiac and chronic obstructive pulmonary disease, high cholesterol, and back and eye problems. All told, blacks have a higher mortality rate and a higher rate of disability in middle age."(Daniels 300) High levels of unresolved stress contribute to these problems experienced by Blacks, as well as other minorities, regardless of SES. Coupled with the additional stresses of a low SES, these problems become multiplied.

Based upon the idea of injustice caused by the inordinate amount of stress placed upon families and individuals in a low SES brackets, an emphasis on their treatment seems a logical place to start. Furthermore, if the problems of stress-induced depression can be prevented through effective means before the age of thirteen, then 
these problems can and should be addressed years ahead of time. It should also address the fact that the least well off in society are the ones who are disproportionately burdened and affected by stress.

How can society be structured in order to create a just solution to these problems? This is exactly where the conception of programs designed to bolster mental health and hardiness becomes an important factor. There are plenty of ways to mitigate the effects of stress: exercise, biofeedback therapy, progressive relaxation techniques, and cognitive behavior therapy. Studies show that the implementation of these techniques can greatly reduce the risk of stress as well as depression. By reducing the chances of or effects of stress, a society in turn reduces the impact of social position throughout life. However large or small of an impact, proper means of coping with stress will over time reduce its effects. Thus, a person or the population they are a part of has a reduction in negative effects.

The question is not where the funds will come from or whether or not the system is capable of achieving this type of program. Rather, it addresses how society should allocate public health endowments. In effect, this type of program not only has compounding interest over time, but it would also be designed to help the least well off in society. It would direct the society's resources in such a way that could create a broader application of the normal range of functioning. Thus, Rawls's conception of a just society becomes however slightly more viable.

This idea seeks to create a society of equal benefits and burdens. It does not seek to bring those of higher SES down but in essence raise those of lower SES up. It 
seeks to rectify the injustices that they face by giving new capabilities and perspectives when dealing with adverse situations.

\section{Alternative Solution for United States}

Now that the problem and the injustices it creates have been identified this thesis will shift to a proposed solution. There is a multitude of ways to address these injustices, from changing society to implementing programs. This thesis holds to the idea that societal change is most effectively created from the ground up. It seeks solutions to the problems caused by stress by teaching individuals to cope because stress is an inevitability of life. Even if benefits and burdens are distributed in a Rawlsian just manner there will still be populations inhibited by stress.

Recognizing the fact that depression, which can be triggered by stress, usually begins by the age of thirteen it would be logical to screen children years ahead of time. It would seem likely that this information and skill sets are best taught to children eight to twelve years of age. Therefore, children could and should be taught effective coping mechanisms in order to mitigate negative circumstances caused by constitutive luck.

This particular cohort is most easily reached through school programs. Since children are legally obligated to go to school for seven hours a day they are a perfect group in which to enact change. Also, since SES typically distributes children to schools, a tactfully placed program could directly impact those children who would need this intervention the most.

Another key factor that could bolster a program designed to promote children's health is the coordinated school health program (CSHP). Developed by the Centers for 
Disease Control, coordinated school health programs have eight components designed to improve children's learning and health. They are Health Education, Physical Education, Health Services, Nutrition Services, Counseling, Psychological, and Social Services, Healthy and Safe School Environment, Health Promotion for Staff, and Family/Community Involvement. ${ }^{20}$ Each facet is geared towards promoting a healthy student body by encompassing all aspects of health. It is easy to envision a program that folds itself into this existing structure.

The program itself would work specifically to aid the CSHP by improving Health Education, Health Services, and Counseling, Psychological, and Social Services. The three techniques could be implemented in the children's weekly health or physical education classes. Physical Education and health teachers could easily learn how to effectively use biofeedback monitors. Children would take to the technique even more easily than their educators similar to how they adapt to other technology.

Imagine teachers implementing the relaxation response with their class to begin each day. They could provide the structure to ensure that the children could practice the technique. Teachers could also guide students through more intricate meditative techniques in rare moments of extra time. Also, it could be an effective tool for the teacher and students to calm down in the middle of a hectic day.

Physical Education classes could act as the basis for screening children for mental illness. Teachers could administer basic surveys/tests to tell if the students show any possible signs of mental duress or illness. These children would then be referred to the school psychologist. The psychologist/counselor could then ask for 
parental permission to begin cognitive behavior therapy. The child does not have to leave school grounds in order to gain the vital mental support that they need. Potentially large portions of the population could have their stress levels decreased daily. Disadvantaged children who need more effective help would benefit from this systematic approach. The hope is that these techniques become instilled in this population. The students would continue to effectively use these techniques well into adulthood decreasing their mental burden and the injustice they face.

\section{Conclusion}

Stress is an inevitable part of everyday life. People of a lower socioeconomic status can face heavier loads of stress throughout their lives because of their social positioning, which is determined by constitutive luck. This constitutes an inequality of circumstances and eventual health outcomes. These portions of the US population not only face economic and social hardship but the mental stress that accompanies it. However, society does not have to continue to function in this way.

A just society provides an environment in which all people can live and flourish. It affords opportunities for individuals regardless of social class or any other personal feature. In order to create this just society, institutions must provide ways to ensure health, which is closely bound to mental health. Proper administration of programs that bolster mental health will help to resolve inequities in health that are created by socioeconomic status.

\footnotetext{
${ }^{1}$ Girdano, Daniel A., Dorothy Dusek, and George S. Everly. "Stress, Stressors, and
} 
Stress Management." Controlling stress and tension. 8th ed. San Francisco: Pearson Benjamin Cummings, 2009. 3-5. Print.

${ }^{2}$ Williams, David. "Socioeconomic Differentials in Health: A Review and Redirection."Social Psychology Quarterly 53.2 (1990): 81-99. Print.

${ }^{3}$ Girdano, Daniel A., Dorothy Dusek, and George S. Everly. "Stress, Stressors, and Stress Management." Controlling stress and tension. 8th ed. San Francisco: Pearson Benjamin Cummings, 2009. 37-41. Print.

${ }^{4}$ Sapolsky, Robert M.. Why zebras don't get ulcers / Robert M. Sapolsky. 3rd ed. New York: Times Books, 2004. Print.

${ }^{5}$ Hamilton, John. "Brain Scientists Uncover New Links Between Stress And Depression : Shots - Health News : NPR." NPR : National Public Radio : News \& Analysis, World, US, Music \& Arts : NPR. N.p., n.d. Web. 19 Nov. 2012. http://www.npr.org/blogs/health/2012/10/15/162934835/brain-scientistsuncover-new-links-between-stress-and-depression

${ }^{6}$ Nagel, Thomas. "Moral Luck." Mortal questions. Cambridge [Eng.: Cambridge University Press, 1979. 24-38. Print.

${ }^{7}$ Kessler, Ronald. "NIMH $\neg \Sigma$ Mental Illness Exacts Heavy Toll, Beginning in Youth." NIMH $\neg \Sigma$ Home. N.p., n.d. Web. 17 Nov. 2012. $<$ http://www.nimh.nih.gov/science-news/2005/mental-illness-exacts-heavytollbeginning-in-youth.shtml>.

${ }^{8}$ Rawls, John. A theory of justice. Cambridge, MA: Belknap Press of Harvard University Press, 1971. Print.

${ }^{9}$ Daniels, Norman. Just Health. Cambridge: CAMBRIDGE UNIVERSITY PRESS, 2007. Print.

${ }^{10}$ Williams, David. "Socioeconomic Differentials in Health: A Review and Redirection*." Social Psychology Quarterly 53.2 (1990): 81-99. Print.

${ }^{11}$ Perkins, Anne. "Saving Money By Reducing Stress." Harvard Business Review 1 Dec. 1994: 12. EBSCO. Web. 17 Nov. 2012.

${ }^{12}$ Unnatural causes. Dir. Larry Adelman. Perf. Researchers. California Newsreel, 2008. DVD.

${ }^{13}$ Benson, Herbert, and Miriam Klipper. "6." The relaxation response. Updated and Expanded The Relaxation Response ed. New York: Morrow, 1975. 111-124. Print. 
${ }^{14}$ Mason, L. John. "Biofeedback: Conversations with a Machine." Guide to stress reduction. Culver City, Calif.: Peace Press, 1980. 133-146. Print.

15 Trudeau, Michelle. "Treating Depression in Adolescents : NPR." NPR : National Public Radio : News \& Analysis, World, US, Music \& Arts : NPR. N.p., n.d. Web. 20 Apr. 2013.

$<$ http://www.npr.org/templates/story/story.php?storyId=1923943\&ps=rs>.

${ }^{16}$ Tylee, André. Personal interview. 16 Aug. 2012.

17 "CDC Data \& Statistics | Feature: An Estimated 1 in 10 U.S. Adults Report Depression." Centers for Disease Control and Prevention. N.p., n.d. Web. 17 Nov. 2012. <http://www.cdc.gov/Features/dsDepression/>.

18 "IAPT Three Year Report." http://www.iapt.nhs.uk. Department of Health, n.d. Web.3 Dec. 2012. <www.iapt.nhs.uk/silo/files/iapt-3-year-report.pdf>.

${ }^{19}$ Burcusa, Stephanie, and William Iacono. "Risk for Recurrence in Depression." Clinical Psychology Review 27.8 (2008): 959-985. Print.

20 "CDC - Coordinated School Health - Components - Adolescent and School Health." Centers for Disease Control and Prevention. N.p., n.d. Web. 20 Apr. 2013. $<$ http://www.cdc.gov/healthyyouth/cshp/components.htm>.

"FASTSTATS - Health Expenditures." Centers for Disease Control and Prevention. N.p., n.d. Web. 17 Nov. 2012. $<$ http://www.cdc.gov/nchs/fastats/hexpense.htm>. 